\title{
A judicialização da saúde: breves comentários
}

\author{
Judicialization health: briefings
}

La judicialización del derecho a la salud: breves comentarios

\author{
Sephora Luyza Marchesini Stival ${ }^{1}$
}

Filomena Girão²

RESUMO: O artigo tem como escopo apresentar a judicialização da saúde, tema que vem tomando espaço nas discussões doutrinárias e jurisprudenciais, onde indivíduos que necessitam de remédios ou tratamentos (simples ou de alto valor), recorrem ao judiciário para terem a concretização do seu direito à saúde. Os magistrados nessas demandas comumente colocam a questão da saúde, como sinônimo de vida, acima de qualquer outra questão, condenando com frequência ao fornecimento de tratamentos/medicamentos, mesmo quando não há a real comprovação dessa necessidade, nem mesmo atentando-se para o dano causado ao coletivo, ao obrigar o Poder Público a gastar uma grande quantia com um só individuo, que já se encontra debilitado. Ocorre que a concessão nessas demandas individuais leva à desarticulação das políticas públicas voltadas para saúde, as quais são propostas e aprovadas pelos Poderes Legislativo e Executivo, valorizando o direito de poucos - os que têm acesso ao judiciário - em detrimento da maioria. Por ser um direito social, o direito à saúde depende das escolhas políticas feitas pelos entes políticos, tendo a sua limitação por questões financeiras ou mesmo técnicas, não cabendo ao Judiciário fazer essas escolhas, nem mesmo impor aos outros Poderes tal fornecimento.

Palavras-chave: Direito à saúde. Medicamentos. Ações Judiciais. Poder Público.

ABSTRACT: The following article aims to present the health judicialization, an issue that has been taken performance in discussions and case law, in which individuals who need drugs and medical treatment (either simple or of a high value) require Judicial Branch in order to take health right provided. Magistrates, in such demands, have figure out the health issue as a synonym of life, over whatever matter, and frequently they have adjudged to provide drugs/treatment, even when there is no real evidence of this need, neither taking into account damage caused to the collective whereas obligate Public Authorities to spend a great amount of funds with a single individual, since he/she is being vulnerable. Granting of these individual demands leads to the dismantling of public policies for health, which are proposed and approved by the Legislative and Executive Branches, what values the rights of the few - those who have got access to Judicial Branch - to the detriment of the majority. Being a social right, the right to health depends

\footnotetext{
${ }_{1}^{1}$ Doutoranda em Direito Civil na Faculdade de Direito da Universidade de Coimbra, Mestre em Crime, Diferença e Desigualdade pela Universidade do Minho. Advogada inscrita na Ordem dos Advogados do Brasil e na Ordem dos Advogados de Portugal. Coimbra. Portugal. E-mail: sephoramarchesini@hotmail.com

2 Licenciada em Direito pela Universidade de Coimbra, com pós-graduação pelo Centro de Direito Biomédico da Universidade de Coimbra. É cofundadora da ALDIS, Ass ociação Lusófona do Dire ito da Saúde, cuja direção integra, e membro da WAML, World Association for Medical Law, Advogada em FAF Sociedade de Advogados, RL. Coimbra, Portugal. E-mail: filomena.girao@faf-advogados.com
} 
on the political choices made by political entities, with their constraints by financial or even technical issues, it is not Judicial Branch competence to make those choices, even impose on other Branches such supply.

Keywords: Right to health. Drugs. Judicial suits. Public Authorities.

RESUMEN: El siguiente artículo tiene como objetivo presentar la judicialización de la salud, un tema que ha ganado espacio en las discusiones doctrinales y jurisprudenciales, en el cual las personas que necesitan de medicamentos o tratamientos (valor simple o alto), recurren al Poder Judicial para tener la aplicación de su derecho a la salud. Los Magistrados, en esas demandas, a menudo plantean la cuestión de la salud como sinónimo de vida, más que cualquier otro tema, sentenciando con frecuencia al financiamiento de tratamientos/ medicamentos, incluso cuando no hay ninguna evidencia real de esta necesidad, ni siquiera reflejan acerca de los daños causados al colectivo cuando obligan el Gobierno a gastar un gran numerario con un solo individuo, que ya se encuentra debilitado. Resulta que la concesión de estas demandas individuales conduce al desmantelamiento de las políticas públicas para la salud, propuestas y aprobadas por las Ramas Legislativa y Ejecutiva, valorando el derecho de unos pocos - los que tienen acceso a la Rama Judicial - en detrimento de la mayoría. Al ser un derecho social, el derecho a la salud depende de las decisiones políticas tomadas por las entidades políticas, con su limitación por cuestiones financieras o técnicas, y no compete al Poder Judicial tomar esas decisiones, incluso imponer a las otras Ramas dicho suministro.

Palabras-llave: Derecho a la salud. Medicamentos. Acciones Jurisdiccionales. Poder Público.

\section{Introdução}

O presente estudo visa expor as nuances da atual situação da judicialização da saúde, assunto esse que traz grande discussão no ambiente doutrinário, já que o direito à saúde, disposto no artigo 6. da Constituição Federal de 1988, insere-se dentro dos direitos sociais, considerados normas programáticas. Is to é, servem de parâmetros para a atividade do Legislador e do Executivo. Os direitos sociais pertencem ao grupo de direitos fundamentais, mas isso não significa que sejam configurados como um direito absoluto e ilimitado, como vem sendo concebido nas sentenças das demandas judiciais de fornecimento de medicamento e/ou tratamentos médicos no judiciário brasileiro.

A saúde em sua acepção é repleta de significados, não podendo ser considerada como a simples ausência de doenças, ao mesmo tempo que não podemos concordar com a significação dada pela Organização Mundial da Saúde (OMS) como sendo "um estado de completo bem-estar físico, mental e social", em virtude de se tratar de uma conceituação para lá de utópica. Não obstante, por se tratar de um Direito de segunda 
geração - um direito social - cabendo ao Estado facilitar o acesso da população a esse direito, deve-se atentar que é mais uma obrigação dentre várias outras, sendo restringida pela chamada reserva do possível - financeira ou técnica - princípio ostentado pelo Poder Público quando demandado nessas situações. Para muitos juristas a reserva do possível serve apenas de "desculpa", como uma questão secundária, enquanto que o direito à saúde, intrinsecamente conectado ao direito à vida, é uma questão primária e de suma relevância.

É aqui que nos deparamos com o grande problema da judicialização da saúde, que, como veremos, é o único direito social cuja concretização o judiciário avoca para si, já que quando o assunto é trabalho, moradia ou mesmo educação, o judiciário não se manifesta com tanto afã. O judiciário quer a resolução dos problemas da saúde no país, ou melhor, dos indivíduos que reclamam mediante um processo judicial a concretização dos seus direitos esculpidos na Constituição Federal. Para isso, condena os entes políticos a torto e a direita com o fornecimento de medicamentos e tratamentos médicos, muitas vezes experimentais e ainda sem eficácia comprovada. Desestruturando o sistema de saúde do país, colocando em causa um direito coletivo e de caráter solidário, como um direito particular, individual, o que leva o judiciário a transformar o Estado em uma "seguradora universal", para aqueles que demandam judicialmente.

Pretende-se assim, com o presente artigo, trazer uma reflexão quanto à atitude dos tribunais de imporem ao Estado o fornecimento de medicamentos e/ou tratamentos de alto valor para uma pequena parcela da população, que teve acesso ao processo judicial para requerê-lo, priorizando a saúde de um determinado indivíduo em detrimento da saúde do coletivo; fazendo-nos questionar até que ponto deve o Estado disponibilizar um medicamento e/ou tratamento de alto custo, para um só individuo, que em muitos casos, já se encontra com a saúde debilitada, mas que teve a oportunidade de apelar ao sistema jurídico para ter o seu direito à saúde concretizado. Enquanto há muitos outros indivíduos, que mal têm acesso ao atendimento básico na saúde, quem dirá a chance de chegar ao judiciário para ter o reconhecimento do seu direito. Ao mesmo tempo, pergunta-se "e se fosse um ente de sua família?", você buscaria todas as possibilidades para aumentar sua expectativa de vida, não importando a existência de inúmeras outras pessoas sem essa possibilidade de requerimento? 


\section{O judiciário brasileiro e os direitos constitucionais}

No meio jurídico brasileiro, há a nítida crença de que a Justiça só se realizará por meio do Poder Judiciário, levando a transferência da competência especifica de discricionariedade legislativa, para uma discricionariedade judicial, sob a alegação de se estar cumprindo a Constituição. De modo que muitos operadores jurídicos (advogados, membros do Ministério Público, entre outros) assumem para si a função de "paladinos da justiça”, onde colocam a Constituição como norma única e que deve ser concretizada em seus termos, deixando de lado as várias normas infra-constitucionais existentes.

Com isso, Scaff (1) defende que a atuação dos tribunais nas demandas de requerimento de medicamento e/ou tratamentos, ao invés de fazerem valer a tónica dos direitos sociais para uma coletividade, criam direitos individuais:

O Poder Judiciário não cria dinheiro, ele redistribui o dinheiro que possuía outras destinações estabelecidas pelo Legislativo e cumpridas pelo Executivo. A tônica das decisões judiciais no Brasil é a implementação dos direitos sociais, mas na verdade atribuem direitos individuais, fazendo com que verbas públicas sejam aplicadas como verdadeiros planos de saúde privada.

Com as decisões condenando os entes federativos a determinadas prestações aos indivíduos que demandam no judiciário, verifica-se uma transferência de recursos públicos que, a priori, serviriam para um grande número de indivíduos em condições de igualdade, para se garantir intangibilidade do direito à saúde de um pequeno número de cidadãos. Com isso, salienta-se que apesar de todos possuírem o direito ao acesso à Justiça, na prática, não é um direito igualitário, pois quem chega às portas do judiciário são aqueles que possuem maior renda e educação (1).

Tecendo considerações ao tema, Nunes (2) reconhece que, por se tratar de um estado democrático, este possui vinculação com a Constituição, não significando isso que o Poder Judiciário possa ultrapassar a sua esfera de competência constitucional. Há uma carência na intenção do juiz de querer alterar a lei de orçamento, que foi aprovada pelo Poder Legislativo - composto por membros escolhidos pela população -, não podendo o mesmo obrigar o Executivo a alterá-la para cumprir a condenação. Nenhum poder pode usurpar a competência do outro, nem mesmo nele interferir. De resto, caso isso fosse permitido, a estrutura do estado democrático ruiria. 


\section{Direito individual $\mathrm{x}$ direito coletivo}

Sarlet e Figueiredo (3) defendem que o direito à saúde não pode ser reduzido a um direito público subjetivo, sendo tutelado tanto na esfera de direito humano como fundamental, havendo uma juricidade em rede em torno desse direito, incluindo a proteção internacional, e não só a nacional, sendo inquestionável que é um direito de todos. Mas, nessa seara, não significa que por se tratar de um direito coletivo, não possa ser objeto de dedução individualizada em juízo. Entretanto, aqui se deve tomar cuidado, pois o uso do judiciário em demandas individuais é crescente, e com as condenações dos entes públicos ao fornecimento dos medicamentos/tratamentos, leva à diminuição dos valores que seriam destinados a toda coletividade, causando prejúzo ao erário.

$\mathrm{Na}$ judicialização da saúde encontramos um dilema entre o direito coletivo e o direito individual. Pois é mais que cristalina a impossibilidade do Poder Público disponibilizar de forma integral o acesso à saúde. No que tange ao art. 196 da Constituição brasileira, Nunes (2) não considera que o direito à saúde exposto nesse dispositivo corresponda apenas ao tratamento de doença e da entrega de medicamentos, e, sim, que de forma emergente deve se preocupar em estabelecer medidas que visem a redução dos riscos de doenças. Pois, como ele mesmo alega quanto ao artigo supracitado, o "STF parece concebê-lo, porém, como um direito individual, cujo cumprimento pode ser exigido diretamente através de uma ação judicial", o que nos faz observar na situação de que "aprisiona-se o interesse social e concede-se realce ao direito individual".

Assim, nesse impasse entre Direito Social a ser requerido por um indivíduo, visando à concretização do direito subjetivo à saúde, percebe-se que "a interpretação que vem sendo dada a este preceito é um direito individual, que pode ser gozado diretamente por cada individuo, e não através da implementação de uma política pública. Aprisiona-se o interesse social e concede-se realce ao direito individual" (2).

Arrematando, Nunes (2) destaca que o direito à saúde é um direito coletivo, e só se realizará corretamente "em benefício de todos e nas mesmas condições para todos", por isso os tribunais devem visar a proteção desse direito, não permitindo que nenhum outro 
diploma legal coloque em causa o serviço nacional "ou as suas características de universalidade, generalidade e gratuidade".

É necessária a atuação do governo para haver a efetivação desse direito a toda a população, mas para isso é preciso inserir a carência desse direito na esfera da ação cívica, sindical e política e não na esfera individual de alguns.

\section{Escolhas políticas}

A proteção à saúde, e consequentemente da vida e da dignidade humana, vem como plano primário de preocupação, colocando-se a escassez de recursos para a sua concretização como uma questão secundária. O interesse financeiro muitas vezes invocado pelo Poder Executivo em ações individuais que pleiteiam medicamentos e/ou tratamentos, é visto com menor importância, como se fosse possível a máquina estatal atender a todas as demandas de direitos subjetivos de todos os cidadãos brasileiros que estivessem acometidos por algum mal - doenças. Ora, não há nenhum país do mundo com recursos financeiros suficientes para atender a "todas as exigências de todos" (2), no que se refere aos direitos sociais, econômicos e culturais. Ainda há outros direitos, as garantias e liberdades também dispostos na Carta Magna, o que obriga à realização de escolhas quanto às despesas a serem feitas pelo Estado, e estas escolhas são políticas.

Quanto às escolhas políticas, essas são arbitradas pelo Poder Legislativo e Poder Executivo em consonância com os ditames da Constituição e as condições financeiras do país, sendo uma questão fundamental para a manutenção do Estado democrático. E isso implica na impossibilidade do Poder Judiciário interferir nessas escolhas - como vem acontecendo com as condenações constantes dos entes estatais a arcarem com despesas de saúde específicas - visto que o Poder Judiciário não possui atribuição para tal (2).

Seguindo esse entendimento, aduzem Capeller e Arnaud (4) que:

A competência para desenvolver políticas publicas cabe ao Poder Executivo, por meio da definição e prioridades e da escolha dos meios para sua realização, e ao Poder Legislativo, por meio da elaboração das leis, inclusive orçamentárias [...] o sistema normativo emitido pelo legislativo é que regula a organização e o funcionamento das instituições destinadas à promoção e defesa da saúde. 
Nunes (2) nos chama a atenção quanto às escolhas, as quais devem ser feitas com base na saúde comunitária, com uma política estruturante e não a de privilegiar poucos indivíduos para o acesso a diagnóstico, tratamento e medicamentos de determinadas doenças. Claramente é uma escolha política, o que demanda uma resposta política, a qual os tribunais não podem ter a pretensão de dar.

O fato de um paciente não encontrar o diagnóstico, o tratamento ou medicamento nos serviços públicos pode ser visto como um descumprimento da Constituição? Para o autor português é descabida esta pergunta, pois, como ressalta, está na própria definição desse direito na Constituição Federal de que o direito à saúde encontra-se dependente da equação financeira, que obriga a ter opções e decisões políticas quanto ao investimento dos recursos públicos que são transformados em prestações especificas. Assim resulta descabido considerar a possibilidade dos tribunais alegarem incumprimento da Constituição.

Com o deferimento desordenado das demandas, condenando o Poder Público no fornecimento de medicamentos e/ou tratamentos, há um esvaziamento dos cofres públicos, e consequentemente há o redimensionamento das Políticas Públicas (4).

Contudo, a atuação do judiciário em condenar os entes públicos, e consequentemente, de levá-los a alterar as escolhas políticas da saúde, não ocorre de igual forma quando o assunto são os outros direitos sociais - educação, moradia, trabalho, etc. O deferimento da demanda envolvendo os outros direitos sociais, à primeira vista não teria cabimento, mas ao beneficiar as considerações que justificam as demandas no âmbito da saúde teriam também de ser consideradas diante desses outros direitos. Como por exemplo, no âmbito do direito ao trabalho, quando um cidadão encontrar-se desempregado, e enquanto passar pelo período em que recebe subsídio de desemprego, poderia recorrer aos tribunais, reclamando um posto de trabalho para que o Estado o disponha? Afinal, se o trabalhador está desempregado contra a sua vontade, há um direito fundamental que não está sendo satisfeito. Assim, poderia o tribunal reconhecer o descumprimento da Constituição? Pois, bem, nesse caso não se vislumbraria.

E no caso do direito à habitação, caso houvesse algum acidente natural que viesse a levar algumas famílias a perderem suas casas, ou mesmo demandas dos moradores 
das favelas do Rio de Janeiro requerendo a habitação adequada, o judiciário consideraria condenar o Estado a realocar todos em novas casas?

No que tange à educação, outro direito social, a situação é a mesma. O ensino público de má qualidade é, sim, um incumprimento da Constituição, mas não é por isso, que há ações nos tribunais requerendo a condenação do Estado para o oferecimento de ensino tal como as escolas particulares, pois provavelmente não seria atendido na mesma medida que a jurisprudência nacional adotou no âmbito da saúde. Até parece um absurdo pensar em cobrar do Estado a disponibilização de um ensino tal como uma escola privada, mas, ao mesmo tempo, o judiciário não considera ser disparatado condenar o Estado ao pagamento de quantias significativas para a compra de remédios topo de linha, com análogos no mercado com preço reduzido, ou até mesmo o pagamento de tratamentos no exterior, mesmo que ainda em fase experimental. Essas são demandas envolvendo o mesmo fundamento que dos requerimentos dos medicamentos, não deveriam ter as mesmas deliberações por tratarem de outros direitos, os quais também estão descritos na Constituição dentro do mesmo rol de direitos sociais? Ressaltando que a doutrina não reconhece nenhum tipo de hierarquia dentre eles. E diante desse quadro, mais uma vez, se desponta a ação despropositada dos tribunais brasileiros nas sentenças de prestação positiva do Estado para com o indivíduo reclamante (2).

Comparando o direito social à saúde com outros direitos sociais ou mesmo com os direitos, garantias e liberdades - segurança (comprovado que a falta de policiamento eleva o grau de violência de determinada rua), acesso à justiça (necessidade da criação de mais comarcas para atenderem a todas as demandas), etc. - também estão prescritos pela Lei Maior de nosso Ordenamento Jurídico. Entretanto, percebe-se que o tratamento dos tribunais é disforme quanto a esses direitos, elevando o direito à saúde como único direito a ser tutelado - leia-se: fazer opções/escolhas políticas - pelo mundo jurídico. Nessa linha, Nunes (2) aponta que "esses direitos só podem ser garantidos através de políticas públicas adequadas e não cabe aos tribunais defini-las nem executá-las, nem sequer fazer juízos políticos sobre a bondade ou grau de cumprimento". Salienta ainda que "o direito à saúde, [...], nos termos da Constituição, é 
garantido pelo Estado mediante políticas económicas e sociais, e não mediante decisões avulsas dos tribunais".

Não obstante, os direitos fundamentais - nesse caso o direito à saúde - não podem ser encarados como direitos absolutos, sem nenhum tipo de condição ou limitação para sua aplicação nos casos concretos. "Nem os tribunais nem as Constituições podem ocupar o lugar que pertence à esfera da luta política, à luta dos povos pelos seus direitos, luta que é, em certa perspectiva, a luta de classes” (2). Pelo contrário, a interferência do judiciário dificulta o acesso aos serviços públicos, pois desarticula o sistema, transferindo o direito daqueles que não possuem condições financeiras para arcar com custas dos medicamentos e/ou tratamentos, nem mesmo têm condições de recorrer aos tribunais em prol da criação de "seguros privados" para determinados indivíduos, que demandam na esfera jurídica.

Aqui se questiona, até que ponto essa atuação do judiciário é constitucionalmente legítima? Se é benéfica para população? Nas palavras de Nunes (2), "em última instância, a questão de saber se o mundo ganhará em ser "governado pelos juízes" (que são, é evidente, tão bons e tão maus como qualquer de nós). E a questão só posso responder que não".

Coutinho (5) sobreleva que os juízes agem de forma sintomática diante das demandas individuais que pleiteiam tratamentos médicos e medicamentos, "dizer não seria como que assinar a sentença de morte do requerente, seria como dizer não à vida e, em tais circunstâncias, chamar para si uma responsabilidade que poderia - e é descarregada, ou seja, algo compreensível diante dos valores que conduzem a cultura do país", o autor acrescenta que "Qualquer um, com um pouco de consciência, faria o mesmo".

\section{Princípio da reserva do possível}

Como já ressaltado, o Executivo quando demandado em ação para fornecer os medicamentos e/ou tratamentos, alega a falta de recursos públicos, para se empregar com as necessidades de apenas um indivíduo ou de uma pequena coletividade, trazendo a lume a teoria da reserva do possível, em que o Executivo deve pesar entre a conveniência e a oportunidade para efetivar determinadas escolhas políticas (2). 
Toda a população contribui para o Fundo de Saúde, e fica a critérios dos entes federativos (União, Estados, Distrito Federal e Municípios) o investimento nas ações e serviços públicos de saúde, e nesta seara há discussão sobre o que os economicistas chamam de "Limite do Orçamento", que no direito chamamos de "Reserva do Possível", que consiste em que todo orçamento possui um limite, e assim deve ser utilizado de acordo com as exigências de harmonização econômica geral.

Bem como, afirma Scaff (1) hoje a expressão "reserva do possível" vem sendo "bastante maltratada pela jurisprudência brasileira, que a hostiliza de maneira praticamente unânime, tudo indica que em virtude de sua má interpretação". Isso porque é por muitos compreendida como argumento da Administração Pública para abster-se de suas obrigações com o direito à saúde, servindo como "refúgio das ordens judiciais", que condenam os entes públicos a prestações de serviços específicas para determinados reclamantes. A Reserva do Possível "é um conceito econômico que decorre da constatação da existência da escassez dos recursos, públicos ou privados, em face da vastidão das necessidades humanas, sociais, colectivas e individuais"(1).

Havendo duas classificações para a reserva do possível, a de caráter econômico e a de carácter técnico. Onde a primeira se aproxima da ideia de escassez, de ausência de meios financeiros, enquanto que a segunda, ocorre com a impossibilidade técnica, podendo ser verificada, por exemplo, com a falta de equipamentos, ou por se tratar de um medicamento que ainda se encontra em fase experimental. O reclamante pode ter a intenção de adquirir, mas veda-se esse objetivo por não estar dentro dos diagnósticos, tratamentos e medicamentos existentes no quadro de saúde do país.

Contudo, a reserva do possível deve ser assimilada com reservas, isso porque cabe aos entes públicos buscarem a maximização dos recursos e minimizarem o impacto da reserva do possível, isto é, "administrar a escassez de recursos e otimizar a efetividade dos direitos sociais". Mas as limitações da reserva do possível não são falaciosas, não sendo uma desculpa genérica dada pelo estado para se eximir de efetivar os direitos sociais. Cabe ao poder público a comprovação da falta efetiva dos recursos indispensáveis à satisfação dos direitos as prestações (3).

Nesta seara, o princípio da proporcionalidade toma destaque, pois deve ser considerado dentro da atuação dos órgãos estatais e particulares. Este princípio deve 
ser verificado em suas duas dimensões "como proibição do excesso e de insuficiência", servindo de parâmetro na atuação do poder público e também pelos órgãos jurisdicionais. O Estado e demais Poderes devem considerar os critérios parciais da adequação, necessidade e proporcionalidade em sentido estrito, para a proteção e efetividade dos direitos, de modo que ao concederem um direito, não permitam que outro direito seja desguarnecido (3).

O Princípio da reserva do possível encontra-se atrelado também ao Princípio da Progressividade, isso porque os direitos sociais não são direitos concedidos em "parcela única", e sim de forma progressiva, que com tempo vai se concretizando. O Direito à saúde só se efetiva com o "desenvolvimento científico e tecnológico da medicina que sempre traz novas respostas aos problemas de saúde existentes, bem como das limitações próprias dos recursos públicos disponíveis" (1).

Por ser o direito à saúde um direito a prestações, os recursos financeiros públicos devem zelar pela constante ampliação dessas prestações, mas estas estarão limitadas pela escassez técnica e também financeira (reserva do possível).

Outro conceito que interfere na efetivação desse direito social são as "escolhas trágicas", denominadas assim por Calabasi e Bobbit (1). As escolhas trágicas são opções escolhidas pela sociedade em determinados assuntos, que trazem consequências que devem ser arcadas por todos. Nisso encontramos um outro princípio, o da Eficiência, e com isso é necessário analisar a cultura de cada sociedade, assim como as suas prioridades, para que as escolhas não se tornem trágicas e sim eficientes.

A crise da efetividade dos direitos fundamentais encontra-se diretamente vinculada com a carência de recursos disponíveis para o atendimento das demandas quanto às políticas sociais. Com menor disponibilidade de recursos, maior é a deliberação responsável quanto à sua destinação, o que carece do melhoramento dos mecanismos de uma gestão democrática do orçamento. Com isso, é imperioso aprimorar, também, o próprio processo de administração das políticas públicas, tanto no plano de atuação do legislador, como do administrador (3).

Para Nunes (2), não há possibilidade de se desvincular a efetivação dos direitos sociais da escassez de recursos, ou seja, da reserva do possível. Ainda, "a 
concretização destes direitos está sempre dependente das escolhas políticas quanto à afectação dos recursos financeiros ao dispor do estado, recursos que, como já se disse, são sempre escassos". E as escolhas políticas estão reduzidas nos orçamentos que são propostos pelo Poder Executivo e que são aprovados pelo Poder Legislativo, não havendo viabilidade dos tribunais sondar se há ou não o incumprimento da Constituição.

Diante disso, como definida, a reserva do possível (Der Vorbehalt des Möglichen) submete os direitos sociais aos recursos financeiros do Estado, de modo que a disponibilidade dessas despesas para o cumprimento dos direitos sociais está inserida no campo discricionário das decisões governamentais e parlamentares - orçamento público. A jurisprudência do Tribunal Constitucional Federal da Alemanha, a partir da demanda sobre o direito ao ensino superior, concluiu que "a prestação reclamada deve corresponder àquilo que o indivíduo pode razoavelmente exigir da sociedade. Com efeito, mesmo em dispondo o Estado dos recursos e tendo o poder de disposição, não se pode falar uma obrigação de prestar algo que não se mantenha nos limites do razoável"(3).

Ainda, em mesma decisão, o Tribunal Constitucional alemão inferiu que a:

[...] reserva do possível, no sentido do que pode o indivíduo, racionalmente falando, exigir da coletividade. Isso deve ser avaliado em primeira linha, pelo legislador, em sua própria responsabilidade. Ele deve atender, na administração de seu orçamento, também a outros interesses da coletividade, considerando as exigências da harmonização econômica geral (1).

Com isso, afirma-se que para se alcançar a universalidade do sistema de saúde, é precisa "lei de ferro da economia da universalidade", na qual os direitos "para serem suportáveis, devem ser limitados", como uma "sustentabilidade do sistema", pois não pode caber a todos o ônus, e somente àqueles, com acesso a justiça, que se beneficiem do investimento de toda sociedade.

Quanto às decisões acerca dos investimentos dos recursos públicos, é preciso que haja transparência nesse exercício, para viabilizar o controle por parte da sociedade. Isso, porque a efetivação dos direitos reconhecidos pela Constituição, encontram-se cingidos às escolhas políticas, e tratando-se de um Estado Democrático, as decisões 
devem ser informadas à população, que é o destinatário por excelência das razões e justificações (3).

\section{A ingerência do Judiciário}

Nunes (2) rechaça claramente a posição intervencionista dos tribunais brasileiros, trazendo várias hesitações que colocam em xeque essa ingerência. Como quando se questiona se hipoteticamente não houvesse uma política pública de saúde - no Brasil há! - por falta de legislação que concretizasse esse direito social, poderiam os tribunais - nomeadamente o STF - decretar a inconstitucionalidade por omissão, mas não poderiam vir a substituir o Legislativo, legislando no lugar deste. Poderia então obrigálos a legislar? E no caso de haver dispositivos, mas os serviços não estarem funcionando, poderia pô-los a funcionar ou condenar o Executivo a fazer? É cristalino que em caso de uma resposta afirmativa estaríamos concordando com a possibilidade do Poder Judiciário poder, não só definir, como executar políticas públicas, o que não cabe a ele!

Entretanto, como sublinha o próprio autor (2), "qualquer decisão de um tribunal que conceda prestações individuais compromete o funcionamento do SUS", afinal "uma política pública estruturada e racionalmente executada não pode estar sujeita a intromissões frequentes", sendo um ato de interferência na competência de outro Poder, contrariando o Princípio da Separação dos Poderes. Isso ocorre quando os tribunais buscam alterar as leis dos orçamentos que o Legislativo aprovou, pois "os orçamentos reflectem opções políticas que os tribunais não podem formular nem julgar (o julgamento político cabe, em última instância. Ao povo soberano) ".

Quanto à intervenção do Juiz em matéria de direitos fundamentais, Andrade (6) aponta três possibilidades. Na primeira, o juiz pode aplicar diretamente a Constituição, quando se constatar a falta de legislação para o caso em apreço. Na segunda, o juiz pode aplicar a Constituição nos pleitos, mesmo havendo lei infra-constitucional, servindo assim para auxiliar na interpretação das leis, pois como bem aponta o autor que:

na maior parte dos casos, as normas albergam vários sentidos ou podem ser, em face dos casos concretos, interpretadas em termos diferentes. Certamente que o Juiz terá de interpretar e aplicar essas normas, sobretudo quando elas tiveram um caráter polissêmico, em conformidade 
com os direitos fundamentais, designadamente com os direitos, liberdades e garantias.

A terceira hipótese é a não aplicação da legislação, por não ser suscetível de interpretar consoante a Constituição.

A atuação dos juízes é uma questão "incontornável", pois se deve aprofundar a análise nas aplicações dos direitos fundamentais prescritos na Constituição feitas pelos juízes, que os desferem nos casos em que há falta de lei, para além dessa, ou mesmo contra. Isso implica a necessidade da observação e manutenção da separação dos poderes, pois "há uma legitimidade política, democrática, que pertence sobretudo ao legislador, e há uma legitimidade jurídica, neste caso, judicial, ligada à realização da justiça, que pertence aos Juízes" (6).

Nisso, é imperiosa a compreensão de que as normas Constitucionais não são absolutas, sendo legítimo que os legisladores venham a restringir direitos, liberdades e garantias das pessoas, e cabendo somente aos tribunais verificarem até que ponto a restrição feita pelos legisladores está sendo adequada, necessária e proporcional. Diferentemente ocorre na situação fática quando há conflito entre os Direitos Fundamentais, caso em que o juiz manifesta-se resolvendo. Depreendem-se também, circunstâncias em que é inevitável a aplicação da Constituição diretamente, como quando se trata de área nova ainda não contemplada na legislação (6).

Outra apreciação feita pelo Andrade (6), é quanto às decisões tomadas pelos juízes nos litígios, na qual pondera que a atuação dos juízes deve visar sempre a interpretação das normas com "consciência comunitária, e, em uma sociedade pluralista, isso pode implicar, muitas vezes, ir contra as convicções pessoais, ideológicas ou morais". No exercício de sua função, está na qualidade de juiz, não podendo agir a título pessoal.

Segundo o raciocínio de Andrade, Sarlet e Figueiredo (3), a atuação dos juristas é necessária, para "zelar pela efetivação dos direitos fundamentais", entretanto, quando estão exercendo esse ato, devem atuar com responsabilidade e com máximo de cautela, para que não haja a violação do princípio democrático e do princípio da separação dos Poderes. O Judiciário deve atentar aos princípios da proporcionalidade e razoabilidade, cabendo ao juiz o papel de condutor da demanda, requerendo que ambas as partes fundamentem o pedido. 
Ainda quando se trata de medicamentos e/ou tratamentos não elencados nos protocolos do sistema de saúde nacional, o juiz tem de solicitar o auxilio a um profissional especializado, que venha a certificar que o pedido exposto na demanda, se atendido, será eficiente e seguro para o requerente.

Percebe-se que o Poder Judiciário adentre nas outras esferas de Poder, com a desculpa de estar cumprindo a Constituição, mas ferindo princípios constitucionais, como o Princípio da Separação dos Poderes. Assim, como, vai contra a lógica democrática instaurada em nosso país, já que não são os juízes investidos do poder dado pela população para atuarem em sua profissão. Por isso, é necessário que diante de casos de judicialização da saúde, o juiz não possa simplesmente deferir, sem atentar-se para todos os elementos alegados pelo indivíduo que pleiteia, como deve abrir espaço para que o ente Público demandado exerça a ampla defesa, não podendo simplesmente decidir frente a incapacidade crônica dos outros poderes. Pois, não cabem ao Judiciário as escolhas políticas, somente, na falta dessas, requerer aos outros Poderes para que haja a sua criação e efetivação.

\section{Considerações Finais}

O termo saúde é plurifacetado, conectando as condições de vida, seja o ambiente ou mesmo o próprio corpo humano, não se limitando apenas à ausência de doenças. Todavia, não pode ser interpretado tão simplesmente como a definição dada pela Organização Mundial da Saúde (OMS) de "bem-estar físico, mental e social", em face das verbas públicas não conseguirem ser suficientes para cobrir com satisfação tal desígnio.

O direito à saúde, como direito constitucional, social, vem sendo frequentemente discutido no Judiciário. Diversas são as demandas contra o Poder Público, para que sejam fornecidos gratuitamente medicamentos e/ou tratamentos de forma individualizada. Com frequência, os tribunais de Justiça brasileiros condenam o Estado a fornecer, sujeito até mesmo à multa diária pelo não cumprimento da obrigação. Todavia, frente aos vários deferimentos de pedidos de medicamentos e tratamentos médicos individuais pela via judicial, com a condenação do Estado quase sempre em 
caráter liminar, verifica-se lesão das políticas de saúde formuladas e aprovadas pelos Poderes Legislativo e Executivo. Assim, observa-se um rombo aos cofres públicos, com o desvio de altas quantias, que seriam investidas no Sistema Único de Saúde (SUS), alcançando a população de forma geral, para abarcar apenas alguns indivíduos - que em boa parte dos casos já se encontra debilitado, com a expectativa de vida reduzida.

Dentro do quadro de impossibilidades da prestação do direito à saúde, encontramos as seguintes limitações fáticas: meios econômico-financeiros e as tecnologias disponíveis. O orçamento público vem mobilizado pelos direitos econômicos, sociais e culturais, dependendo do quadro constitucional e de opções politicolegislativas. Em seguida, deparamo-nos com as impossibilidades técnicas - que não deixam de estar relacionadas com o requisito financeiro - responsáveis pela ausência de aparatos técnicos para a efetivação da saúde em determinados casos, como nos medicamentos e tratamentos que se encontram em fase experimental ou que ainda não estão reconhecidos pelo sistema nacional.

Essa limitação financeira e técnica não é bem recebida pelos juristas, os quais, em sede de liminar, condenam o Poder Público, sem que esse possa apresentar sua defesa - as limitações do orçamento público ou mesmo a disponibilização de meios alternativos para os medicamentos e/ou tratamentos demandados - ou mesmo sem verificar se o que é pleiteado pelo requerente é possível de se deferir, pois, como bem demonstrado nesse estudo, os juízes temem negar o pedido, como se fosse sinônimo de "sentença de morte" para aquele indivíduo. Ainda a interpretação que fazem do direito à saúde descrito na Constituição Federal é colocado como absoluto e ilimitado, por estar intimamente vinculado com a vida, o que não pode ser considerado verdade.

Os direitos sociais visam o atendimento a todos, de forma universal, tendo esse rol de direitos como fim maior a solidariedade para aqueles com menores condições. É um direito coletivo, que só assim alcançará a sua eficiência, e nunca através da concessão em demandas individuais. E, diante disso, essas medidas avulsas devem deixar de interferir no desenvolvimento do Sistema Único de Saúde. O judiciário deve, sim, suprir a inanição dos outros Poderes, mas de forma coletiva, como com a condenação para a inclusão de medicamentos ou tratamentos nos protocolos do sistema nacional, fazendo revisões constantes nesses protocolos, e não obrigando o ente Público a desviar 
quantias vultosas de dinheiro em prol de um indivíduo específico. Nem mesmo o juiz tem direito a escolher quem merece mais o acesso à saúde.

O juiz, ao deparar-se com esses casos, deve de forma cuidadosa equacionar o direito à saúde, atentando-se para uma gama de questões que devem ser analisadas, como a situação do indivíduo, a realidade em torno deste (cultural, social, geográfica e climática, etc.), junto dos limites fáticos e jurídicos.

O direito à saúde é um direito que causa dispêndios financeiros ao Poder Público e por isso "deve ser distribuído desigualmente entre os desiguais, visando a redução de suas desigualdades, o direito à saúde não consagra direitos individuais, mas direitos difusos" (1), e a melhor forma de alcançá-lo é diretamente com o Poder Legislativo para formulação de políticas públicas - e ao Poder Executivo - implementação de políticas públicas - e não pela via judicial e de forma individualizada.

Para finalizar, deve-se atentar que "a saúde depende, ao mesmo tempo, de características individuais, físicas e psicológicas, mas também, do ambiente social e econômico, tanto daquele mais próximo das pessoas, quanto daquele que condiciona a vida dos Estados e que, portanto, ninguém pode, individualmente, ser responsável por sua saúde"(7).

\section{Referências}

1 - Scaff, FF. Direito à Saúde e os Tribunais. In: Nunes AJA, Scaff FF. Os tribunais e o Direito à Saúde. Porto Alegre: Livraria do Advogado, 2011.

2 - Nunes AJA, Scaff FF. Os tribunais e o Direito à Saúde. Porto Alegre: Livraria do Advogado, 2011.

3 - Sarlet IW, Figueiredo MF. Reserva do Possível, mínimo existencial e o direito à saúde: algumas aproximações. In: Sarlet IW, Timm LB, organizadores. Direitos Fundamentais: orçamento e "reserva do possível". $2^{\mathrm{a} e d}$. Porto Alegre: Livraria do Advogado; 2013. p. 13-50.

4 - Capeller W, Arnaud AJ. Cidadania e direito à saúde. In: Costa AB et al. organizador. Série $O$ Direito achado na rua: Introdução crítica ao direito à saúde. Curso de extensão Universitária à distância. Brasília: CEAD/UNB, 2009, p. 107.

5 - Coutinho JNM. Da política pública ditada pelo poder judiciário no tocante á saúde pública. Revista do Instituto de Pesquisa e Estudos: Divisão Jurídica. Instituição Toledo de Ensino. Bauru, SP: A Instituição, 1996, 1:179-186. 
6 - Andrade JCV. O judiciário e os direitos fundamentais sociais. Tribunal de Justiça do Rio Grande do Sul - Centro de Estudos; 2002. Palestras.

7 - Dallari SG. O conteúdo do direito a saúde. In: Costa AB et al., organizadores, Série O Direito achado na rua: Introdução crítica ao direito à saúde. Curso de extensão Universitária à distância. Brasilia: CEAD/UNB; 2009.

\section{Como citar este artigo:}

Stival SLM, Girão F. A judicialização da saúde: breves comentários. Revista Cadernos Ibero-Americanos de Direito Sanitário. 2016 abr./jun, 5(2):142-159. 